NEUES AUS DER INDUSTRIE

\section{INTECO erhält weitere Aufträge von Fushun Special Steel, China}

Der österreichische Anlagenbauer wird 2016 insgesamt drei neue Anlagen an den chinesischen Edelstahlproduzenten und mittlerweile Stammkunden Fushun Special Steel ausliefern.

Bereits Ende November 2015 beauftragte Fushun INTECO mit der Konstruktion und Lieferung einer $20 \mathrm{t}$ ESU Anlage, welche in enger Zusammenarbeit mit INTECO Dalian, als lokalen Fertiger, abgewickelt werden wird. Das sehr ausgeklügelte Anlagenkonzept basiert auf zwei Ofenköpfen, die in drei Schmelzstationen Blöcke mit einem maximalen Blockdurchmesser von ca. $1200 \mathrm{~mm}$ und max. $30 \mathrm{t}$ erzeugen.

Überzeugt von der Kompetenz und Flexibilität von INTECO wurde nun am 27. Jänner der Auftrag für eine weitere ESU Anlage nach gleichem Konzept, nur in etwas kleinerer Ausführung (max. Durchmesser von ca. 750 mm

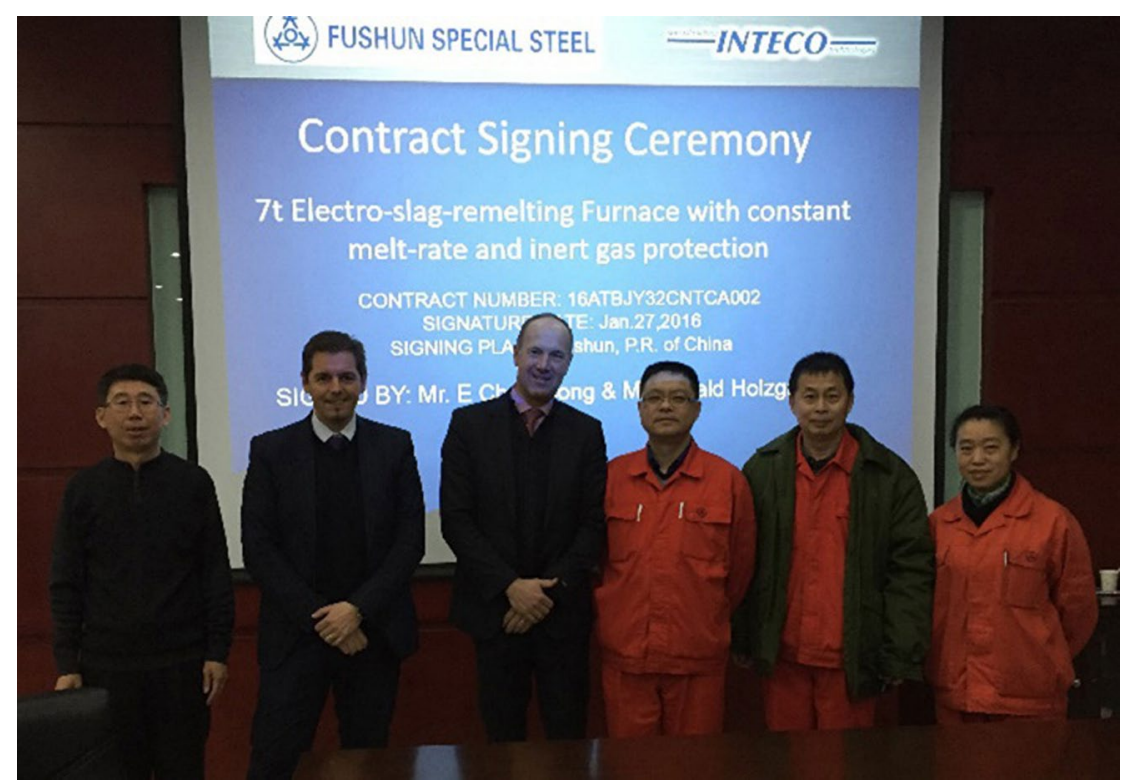

und max. Blockgewicht von 7 t) unterzeichnet.

Mit dem Mitte 2015 erteilten Auftrag über eine Druck ESU Anlage arbeiten INTECOs Konstrukteure im Moment eifrig an insgesamt drei Anlagen für Fushun. Die Montage und Inbe-

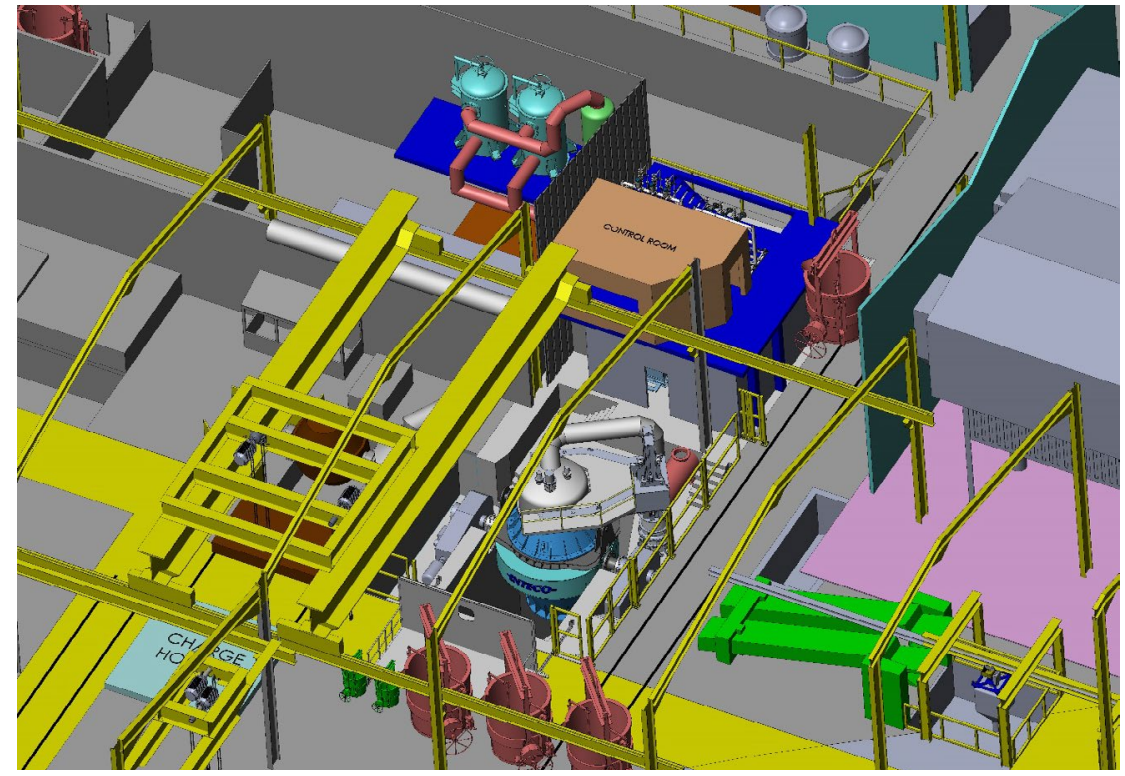

triebnahme für alle drei Anlagen wird im Herbst dieses Jahres beginnen.

\section{INTECO erhält neuen Auftrag von Goodwin Steel Castings Limited, UK}

Im Dezember 2015 gelang es INTECO, den Auftrag zum Engineering einer $30 \mathrm{t}$ VODC Konverter für Goodwin Steel Castings Limited, einem hochqualitativen Hersteller mittelgroßer Gussteile, zu gewinnen. Das ausgeklügelte Anlagenkonzept wird es Goodwin ermöglichen, sowohl normale AOD Behandlungen als auch Vakuumbehandlungen in derselben Anlage durchzuführen um dadurch noch höhere Stahlqualitäten produzieren zu können.

INTECO hat bereits mit der Auslegung und dem Engineering begonnen und im Juni 2016 abgeschlossen haben. Goodwin plant, mit der Anlage im Dezember 2016 in Betrieb zu gehen, und wird INTECO zur Lieferung des Equipments und zur Inbetriebnahme voraussichtlich in der ersten Hälfte des Jahres 2016 beauftragen. 